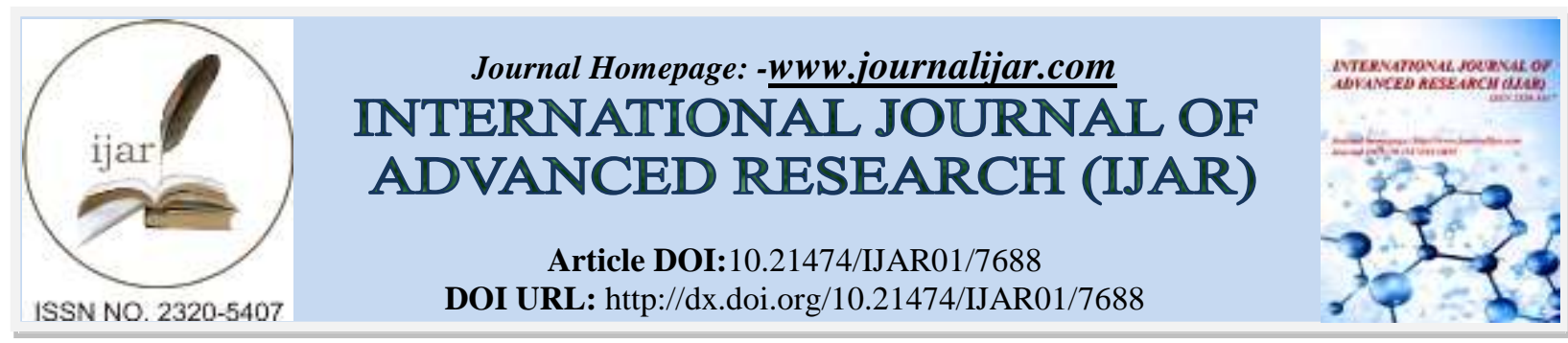

RESEARCH ARTICLE

\title{
COMPARATIVE STUDY OF THE ANTIBACTERIAL ACTIVITY OF CINNAMON AND ORIGAN ESSENTIAL OILS AND THEIR PRIMARYCOMPONENTS ON AVIAN Escherichia coli STRAINS.
}

\section{Khribch Jamila $^{1}$, Smara Naima ${ }^{1}$, Laghrib Farida ${ }^{1}$, Zrira saadia $^{2}$, Nassik saâdia ${ }^{3}$, EL Houadfi Mohammed ${ }^{3}$ and Oukessou Mohamed ${ }^{1}$.}

1. Department of Biological and Pharmaceutical Sciences, Hassan II Agronomic and Veterinary Institute, BP 6202, 1010, Rabat, Morocco.

2. Department of Food and Nutrition Sciences, Agronomic and Veterinary Institute Hassan II, BP 6202, Rabat, Morocco.

3. Avian Pathology Unit, Department of Pathology and Veterinary Public Health, Agronomic and Veterinary Institute Hassan II, BP 6202, Rabat- Institute, Rabat, Morocco.

\section{Manuscript Info}

Manuscript History

Received: 18 July 2018

Final Accepted: 24 August 2018

Published: September 2018

Keywords:-

Aromatogram, essential oil, resistance,

poultry, oregano, cinnamon,

cinnamaldehyde, carvacrol.

\begin{abstract}
The emergence of bacterial resistance to the usual antimicrobial agents is nowadays a major challenge in therapeutics for both humans and animals. As a result, the search for new antimicrobial agents has become a necessity. In this context, a great interest was focused on naturally occurring substances with antibacterial activity. The present study consists of evaluating the antibacterial activity of two essential oils (EO) from two aromatic and medicinal plants commonly used in humans in Morocco, namely, oregano (origanum vulgare) and cinnamon (Cinnamomum cassia), and their primarycomponents, carvacrol and cinnamaldehyde respectively, against antibioticresistantEscherichia coli strains of avian origin. Extraction of the EO was carried out by hydrodistillation, and their chemical analysis was carried out by gas chromatography (GC).The cinnamon EO is mainly composed of cinnamaldehyde (nearly 90\%), followed by betacaryophyllen (6.1\%), cinnamyl acetate and eugenol with $(2.75 \%)$ and $(0.46 \%)$; carvacrol is the primary component of oregano EO (65.51\%), followed by gamma-terpinene $(11.49 \%)$, p-cymene $(6.27 \%)$, thymol $(4 \%)$ and borneol $(3.58 \%)$. The aromatogram showed interesting antibacterial activity of EO and their active ingredients against the used bacterial strains. The diffusion method on agar medium showedthat EO of cinnamon was more active than oregano EO against E. colistrains, with mean inhibition zones of $25.8+4.5 \mathrm{~mm}$ and $17+3.7 \mathrm{~mm}$, respectively. The obtained MICs showed also that cinnamaldehyde was more potent than carvacrol, with average MICs of $0.039 \%$ and $0.106 \%$, respectively.
\end{abstract}

Copy Right, IJAR, 2018,. All rights reserved.
Corresponding Author:- Khribch Jamila.

Address:- Department of Biological and Pharmaceutical Sciences, Hassan II Agronomic and Veterinary Institute, BP 6202, 1010, Rabat, Morocco. 


\section{Introduction:-}

During le few last decades, the use of antibiotic agents (AB) encountered two major constraints namely the emergence of antimicrobial resistance andthe strong consumer awareness on the health impact of drug residues in food of animal origin. In front of this situation, the discovery of new antibacterial agents has become more than indispensable. To be innovative and bypass aforementioned problems, the new generation of antibiotics should be safe for the consumer and not or less subjected to bacterial resistance. One of the most promising alternatives toreach such an objective would be the exploration of natural resources as they constitute, by their biodiversity, the largest reserve of bioactive substances. Among these alternatives, plant extracts including essential oils (EO) have a high potential to replace antibiotics.

Essential oils (EO) are aromatic and volatile oily liquids obtained from plant material. They are naturally formed in special cells or groups of cells found in leaves and stems (Oussalah and al., 2006). Although the antibacterial properties of EO have long been recognized, the recent interest in natural derived antimicrobials has led to renewed scientific interest in these substances. Indeed, EOs have many biological properties including antibacterialeffects, without development of resistance phenomenon, antioxidant activity and the stimulation of the immune and digestive processes (Bouhdid and al., 2009). Their antimicrobial activity has been shown in vitro by numerous studies (Smith-Palmer andal., 1998; Hammer andal., 1999; Dorman and Deans, 2000; Elgayyar andal.,2001), primarily against pathogenic bacteria such as Clostridium perfringens, Escherichia coli, Staphylococcus aureus, Salmonella typhimurium, Listeria monocytogenes and Yersinia enterocolotica (Dorman and Deans, 2000; Fabio andal., 2003). Antimicrobial activity of EO is particularly assigned phenols (such as carvacrol, thymol and eugenol), alcohols (such as linalool) and aldehydes (such as cinnamaldehyde). Thus, the antibacterial activity of an EO is determined byits level of these constituents (Bouhdid and al., 2009).

The objective of the present study was to evaluate thein vitro antibacterial activity of two essential oils, namely, Origanum vulgare EO and Cinnamomum cassia OE and their major components, carvacrol and cinnamaldehyde, on Escherichia coli strains of avian origin resistant to Enrofloxacin and Florfenicol.

\section{Material And Methods:-}

\section{Materiel}

\section{Active materials}

The essential oils of cinnamon (Cinnamomum cassia) and oregano (Origanum vulgare), obtained by hydrodistillation, were provided by the agro-food laboratory of IAV Hassan II Institute.

Cinnamaldehyde (>95\%) and carvacrol $(>98 \%)$ were purchased from Sigma-Aldrich.

\section{Bacterial strains}

The antibacterial activity of essential oils and their active ingredients was evaluated on Escherichia coli reference strain (ATCC25922) and on 40 Escherichia coli strains of avian origin isolated and identified in the laboratory of Avian Pathology at the IAV Hassan II Institute. The isolation of E. coli was made from the lung, liver, heart, bone marrow of the broiler.

\section{Methods:-}

\section{Essential oil extraction}

The apparatus used for the hydrodistillation of essential oils is of the Clevenger type (Clevenger, 1928). It consists of a balloon heater, a Pyrex glass flask where the dried plant is placed and distilled water, a vapor condensing column (refrigerant) and a Pyrex glass collector which also receives the distillation extracts. The essential oils obtained are stored in a refrigerator in a brown glass bottle sealed at $4{ }^{\circ} \mathrm{C}$ and in the shade.

\section{Essential oil chemical analysis}

The obtained EO were analyzed by gas chromatography (GC) according to the following conditions: Chromatograph: PEKRIN ELMER Autosystem XL; Detector: FID; Column: ELITE PE-5; Injector temperature: 250

${ }^{\circ} \mathrm{C}$; Detector temperature: $340^{\circ} \mathrm{C}$; Temperature program: $50^{\circ} \mathrm{C}(4 \mathrm{~min}), 5^{\circ} / \mathrm{min}, 230^{\circ}$ (20min); Injection volume: $0.02 \mathrm{ml}$ using a syringe; Carrier gas: N2 (nitrogen); Flow rate of the carrier gas: $1 \mathrm{ml} / \mathrm{min}$.

\section{Determination of Antimicrobial Activity}

The antibacterial activity of EO was evaluated using two different methods. 


\section{The Aromatogram}

The aromatogram technique (diffusion technique in solid medium) is used to evaluate the sensitivity of bacteria to EO (Yashphe andal., 1979). Pure EOs are dispersed in $0.2 \%$ agar solution, to promote contact between germs and compounds. According to the method described by Remmal andal.,(1993a),a 10\%initial emulsion is prepared by adding $100 \mu \mathrm{l}$ of EO to $900 \mu \mathrm{l}$ of a sterile aqueous solution containing $0.2 \%(\mathrm{w} / \mathrm{v})$ of agar. Then sterile petri dishes $(9 \mathrm{~cm})$ containing $9 \mathrm{ml}$ of Muller-Hinton medium were inoculated with the bacterial suspension of a density of $10^{6}$ $\mathrm{CFU} / \mathrm{ml}$ of medium; after solidification of the medium, $6 \mathrm{~mm}$ diameter sterile disks, made from the Whatmanpaper, were deposited on the surface of the medium and impregnated with $5 \mu$ of the solution of EO, Carvacrol or Cinnamaldehyde. In the case of the combinationof two products, each solution was used at $2.5 \mu$. The petri dishes are then placed at a temperature of $+4^{\circ} \mathrm{C}$. for about one hour, and then incubated at $37^{\circ} \mathrm{C}$. for 18 to 24 hours. The sensitivity of the organisms tested with EO is characterized by the formation of a clear circle (zone of inhibition) around the disks containing these oils. The inhibitory effect of EO was evaluated by determining the diameter of the inhibition zone formed in mm (Matasyoh and al., 2007).

\section{Macrodilution technique in a liquid medium}

The minimum inhibitory concentration (MIC) of the EO was determined by the macrodilution method (Remmal andal., 1993). Briefly, a stock solution is obtained by dissolving $20 \mu \mathrm{l}$ of EO solution with $0.2 \%$ of agar in $2 \mathrm{ml}$ of TSB, then serial dilutions of the obtained concentration(between $1 \%$ and $0.0039 \%(\mathrm{v} / \mathrm{v})$ ) were carried out in tubes containing $1 \mathrm{ml}$ of TSB broth. A seeded tube without EO was used as a positive control and, sometimes, a tube containing EO alone serves as a negative control. The different tubes are inoculated with $10 \mu \mathrm{l}$ of the bacterial suspension with a density of $10^{6} \mathrm{CFU} / \mathrm{ml}$. The tubes containing different concentrations of EO and the positive control are incubated at the same time at $37^{\circ} \mathrm{C}$ for $18-24$ hours. The minimum inhibitory concentration (MIC) is the lowest concentration of oil to which no bacterial growth is visible to the eye after incubation for 24 hours at $37^{\circ} \mathrm{C}$ (NCCLS, 1999).

\section{Results And Discussion:- \\ Essential oil chemical analysis \\ Chemical composition of EO of cinnamon}

The composition of cinnamon EO used in our study is given in Figure 1. This figure indicates that Cinnamaldehyde is the main component accounting for almost $90 \%$, followed by beta-caryophyllen $(6.1 \%)$, cinnamyl acetate $(2.75 \%)$ and eugenol $(0.46 \%)$. These results are somewhat different from those specified by the European Pharmacopoeia. Indeed, according to the European Pharmacopoeia (2011), levels of the cinnamaldehyde isup to 75\%, and those of eugenoland $\beta$-caryophyllene are up to $7.5 \%$ and 1 to $4 \%$ respectively.Theses differences might be ascribed to multiple factors such as extraction mode and analysis technique.

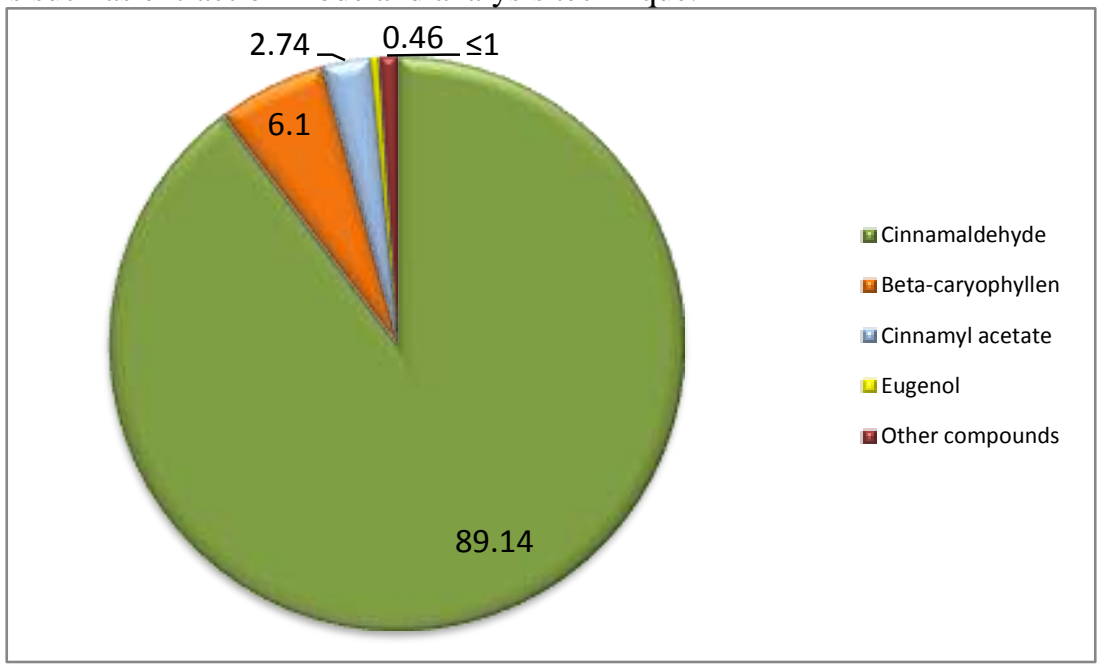

Figure 1:-Chemical composition of cinnamon EO

\section{Chemical composition of EO of oregano:-}

The figure 2 shows chemical composition of the EO of oregano (origanum vulgare). Overall, 25 constituents, dominated by carvacrol $(65.51 \%)$ were identified. The others components were gamma-terpinene $(11.49 \%)$, p- 
cymene (6.27\%), thymol (4\%) and borneol (3.58\%); linalool, alpha-terpinene were detected with values less than $1 \%$. Our results are qualitatively, but not quantitively, in agreement with the results reported by Bouhdid and al., (2008) and Hammouand al., (2011), who showed that the most represented compound in the EO of oregano is carvacrol (30.53\% and 36.31\%), followed by the thymol (27.50\% and $16.88 \%)$ according both studies respectively.

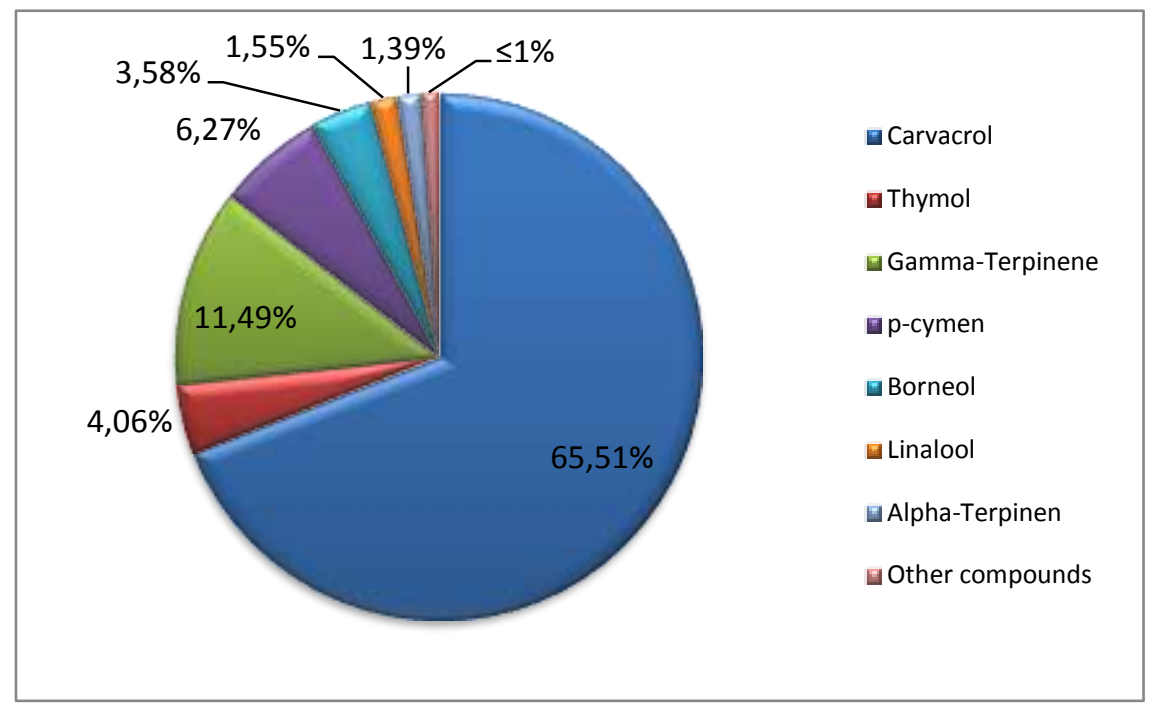

Figure 2:-Chemical composition of oregano EO

\section{Antibacterial activity of essential oils}

Out of a total of 40 strains, cinnamon's EO was found to be the most effective against bacteria with an average of $25.8+4.5 \mathrm{~mm}$ inhibition zones compared to $17+3.7 \mathrm{~mm}$ with oregano $\mathrm{EO}$ (figure 3 ).

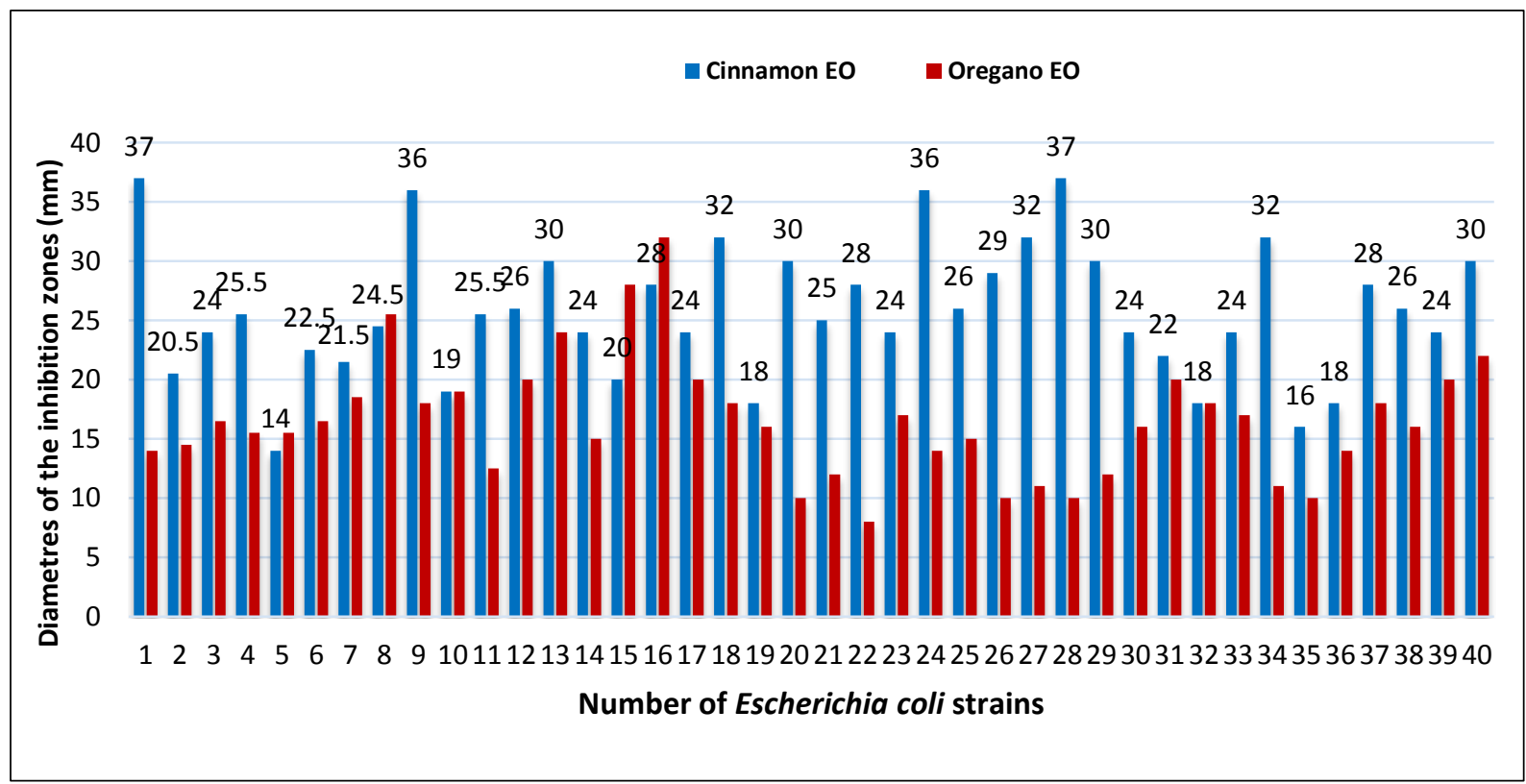

Figure 3:-Inhibition zone diameters $(\mathrm{mm})$ generated by the EO of cinnamon and oregano on E.coli strains of avian origin

The EO of cinnamon and oregano are among the EO with the strongest antibacterial power (with thyme, savory and clove). The bactericidal activity of cinnamon EO has been described on various strains of Escherichia coli, with a power exceeding streptomycin (Senhaji and al., 2007). The antibacterial effect of oregano EO against $E$. coli has been reported by many studies (Ultee and $a l ., 2002$ ). 
The superiority of cinnamon EO compared to that of Oregano observed in our study agrees with the result observed by Bouhdid and $a l$., (2012) has been confirmed in several studies, including the one conducted, while oregano has shown interesting antibacterial activity, particularly against strains of $S$. aureus. However, strains of Ps. Aeruginosa expressed some resistance to this oil. These strains were more sensitive to cinnamon EO which is predominantly composed of cinnamaldehyde (Inouye and al., 2001; Friedman and al., 2002). Our results also agree with those of Mithandal., (2014), commercial cinnamon (Cinnamomum cassia) and oregano (Origanum compactum) essential oils were tested by diffusion technique, against some pathogenic bacteria, cinnamon EO expressed an effect significant inhibitor and superior to that of Oregano, Listeria monocytogenes, Salmonella Typhimuriumand Escherichia coli (Mith and $a l$. , 2014). These promising antimicrobial effects can be attributed to the presence of major bioactive constituents, including cinnamaldehyde and carvacrol. Our results differ from those of Valero and Salmeron (2003), because among 11 essential oils tested against Bacillus cereus, Oregano EO was more active than Cinnamon EO (Valero and Salmeron, 2003). The essential oils of oregano and cinnamon are potential candidates for an application in the treatment of infections. These two essential oils act by increasing membrane permeability, inducing collapse of membrane potential and inhibiting respiratory activity, leading to a loss of cell viability (Bouhdid and $a l$., 2012).

Antibacterial activity of the purecomponents (Cinnamaldehyde and Carvacrol) Activity on reference bacterial strains

The EO of cinnamon and its main active ingredient cinnamaldehyde showed a higherantibacterial activity than the EO of Oregano and carvacrol. Similarly, the activity of cinnamon EO was, on average, more potent than that of cinnamaldehyde (Table 1).

Table1:-Inhibition zone diameters ( $\mathrm{mm})$ generated by tested products on the reference E. coli strain.

\begin{tabular}{|c|c|c|c|c|c|}
\hline Test & Cinnamon EO & Cinnamaldehyde & Oregano EO & Carvacrol & $\begin{array}{c}\text { Cinnamaldehyde + } \\
\text { Carvacrol }\end{array}$ \\
\hline 1 & 26 & 29 & 16 & 21 & 32 \\
\hline 2 & 32 & 24 & 18 & 25 & 34 \\
\hline Average \pm SD & $29 \pm 3$ & $26,5 \pm 2,5$ & $17 \pm 1$ & $23 \pm 2$ & $33 \pm 1$ \\
\hline
\end{tabular}

The E. coli strain showed variable sensitivity to EO and pure components. It is more sensitive to cinnamon EO than it is to cinnamaldehyde, but more sensitive to carvacrol than oregano EO. However, the cinnamaldehyde and carvacrol combination showed greater inhibitorypower than cinnamaldehyde and carvacrol alone. The antibacterial activity of cinnamaldehyde has been mentioned in the work of Mith and al.,(2014) who have shown that this active principle has high antimicrobial activity against E.coli ATCC 35150; E. coli O157: H7 S0575; Salmonella typhimurium ATCC14028 and Pseudomonas fluorescens ATCC1352, whereas carvacrol, with the exception of P. florescence, had a lower activity. This result is consistent with our observation in the present study. However, according to another study, carvacrol had the strongest effect against Listeria monocytogenes, followed by thymol, eugenol, cinnamaldehyde and iso-eugenol (Yamazaki and al., 2004).

\section{Avian strains}

Cinnamaldehyde + Carvacrol and their association

Ten avian strains $E$. coli resistant to enrofloxacinbut sensitive to colistin were tested to evaluate the inhibitory effect of cinnamaldehyde and carvacrol and their association. The results of the aromatogram are shown in Table 2.

Table 2:-Inhibition zone diameters ( $\mathrm{mm})$ generated by the active products and their association for $\boldsymbol{E}$. coli avian

\begin{tabular}{|l|c|c|c|}
\hline \multicolumn{1}{|c|}{ Test } & Cinnamaldehyde & Carvacrol & Cinnamaldehyde+ Carvacrol \\
\hline 1 & 20 & $\mathbf{1 6}$ & $\mathbf{3 0}$ \\
\hline 2 & 22 & 20 & 40 \\
\hline 3 & 30 & 20 & 40 \\
\hline 4 & 28 & 30 & 28 \\
\hline 5 & 32 & 20 & 24 \\
\hline 6 & 32 & 20 & 26 \\
\hline 7 & 28 & 20 & 36 \\
\hline 8 & 32 & 16 & 30 \\
\hline 9 & 36 & 22 & 32 \\
\hline
\end{tabular}




\begin{tabular}{|l|l|l|l|}
\hline Average \pm SD & $30 \pm 4$ & $20 \pm 3$ & $31 \pm 5$ \\
\hline
\end{tabular}

The pure components showed antimicrobial activity which resulted in varying zones of inhibition depending on the product. They ranged from $14 \mathrm{~mm}$ to $30 \mathrm{~mm}$ for carvacrol and from $20 \mathrm{~mm}$ to $38 \mathrm{~mm}$ for cinnamaldehyde. Corresponding respectively to means of $20 \pm 3 \mathrm{~mm}$ and $30 \pm 4 \mathrm{~mm}$. For the cinnamaldehyde and carvacrol combination, the mean value was $31 \pm 5 \mathrm{~mm}$ with variations of 24 to $40 \mathrm{~mm}$ depending on the strain. The results confirm the high antibacterial activity of cinnamaldehyde compared to carvacrol on E. coli strains.

\section{Essential oils and theirmajor active ingredients}

The results show that the highest inhibitory effect against avian E. coli strains was obtained with cinnamon products, with mean values of $25.1 \pm 4.3 \mathrm{~mm}$ and $23.35 \pm 5.4 \mathrm{~mm}$ for EO and cinnamaldehyde respectively. While these values averaged only $16.7 \pm 2.2 \mathrm{~mm}$ and $19.35 \pm 1.6 \mathrm{~mm}$ for oregano EO and carvacrol respectively. The figures 4 and 5 illustrate this aspect.

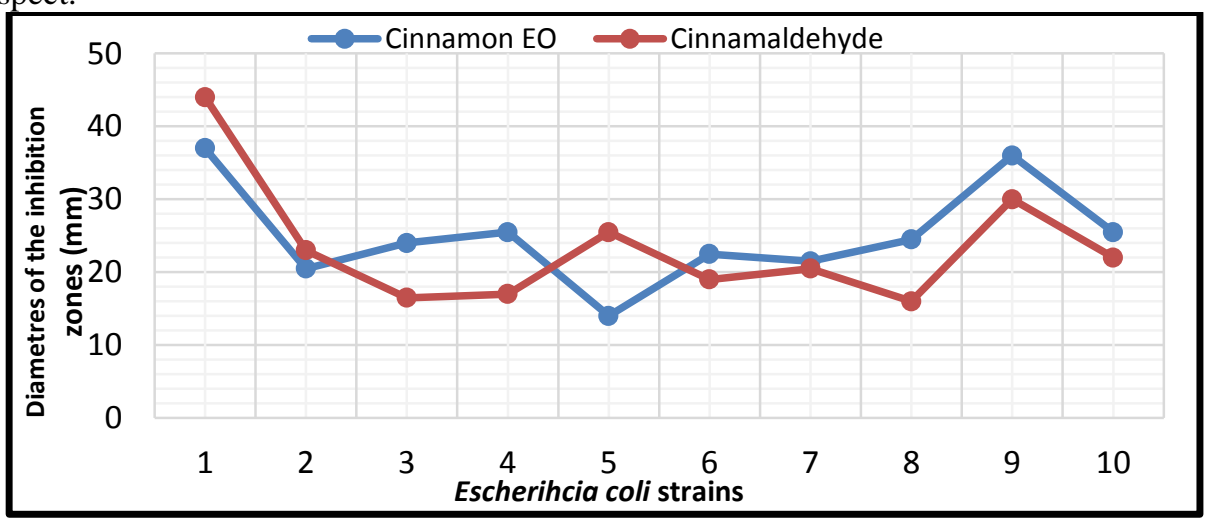

Figure 4:-Comparison of the activity of the EO of Cinnamon and cinnamaldehyde

The antibacterial activity of cinnamon EO was, on average, more potent than that of cinnamaldehyde (Figure 4). This suggests that the minority compounds present in the EO have a significant effect. On the other hand, the figure 5, shows that carvacrol is more powerful than oregano EO. This could suggest that antimicrobial activity of the oregano EO is mainly due to carvacrol which represents only $65 \%$ in this EO in our study. This result might be also explained by the presence of antagonistic molecules in the EO.

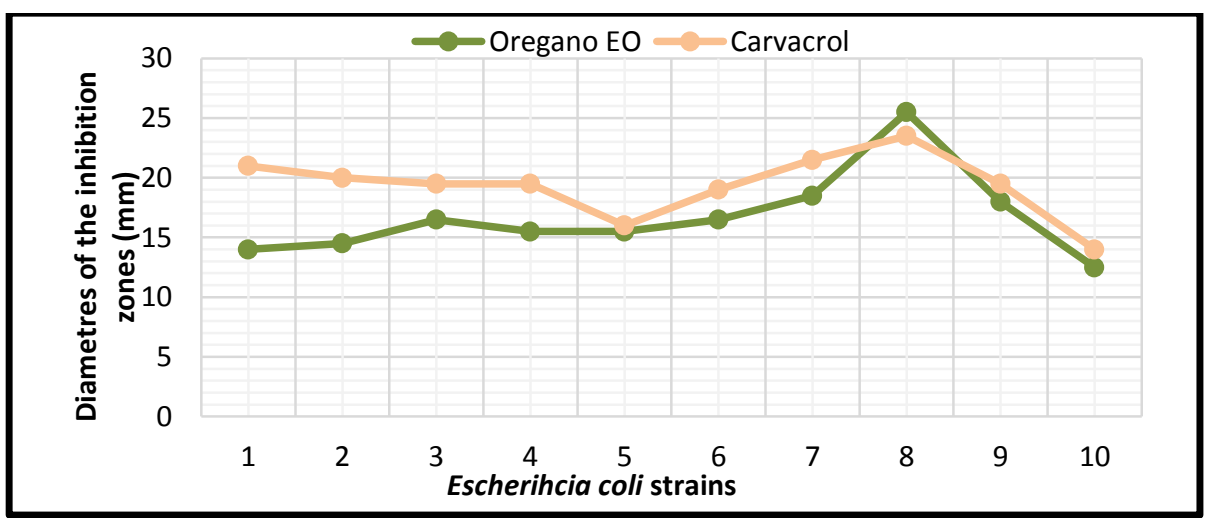

Figure 5:-Comparison of the activity of the EO of oregano and carvacrol

Referring to the results obtained in the present study, it is legitimate to conclude that the antibacterial activity of EO is directly influenced by the nature and the proportion of their constituents. The most represented compounds are often responsible for the observed antibacterial activity (Dormans and Deans 2000; Kalemba and Kunicka 2003). But according to several authors (Chorianopoulos and al., 2004; Sokmen and al., 2004; Peñalver andal., 2005; Bounatirou and al., 2007; Cao and al., 2009), in addition to major compounds, secondary components interact with each other to give an antimicrobial effect to EO. Some studies have concluded that minor components play a role in activity and may have an effect or influence the EO overall activity (Gill and al., 2002; Rota and al., 2008). 
According to Kalemba and Kunicka (2003), the sensitivity of a microorganism to EO depends on the properties of the latter and the microorganism itself. In general, Gram- bacteria are more resistant than Gram + due to the structure of their outer membrane. Indeed, the outer membrane of Gram- is richer in lipopolysaccharides and proteins that make it more hydrophilic, and thus prevents hydrophobic terpenes from adhering to it. Nevertheless, some low molecular weight phenolic compounds such as thymol and carvacrol may adhere to these bacteria by attachment to membrane proteins and lipopolysaccharides through their functional groups and thereby reach the more vulnerable inner membrane (Dorman and Deans, 2000).

Minimal Inhibitory Concentration of active ingredients:-

MICs of cinnamaldehyde and carvacrol were calculated using ten E. coli strains of avian origin (Figure 6). The average MIC values for each of the active ingredients are $0.039 \%$ and $0.106 \%$ for cinnamaldehyde and carvacrol respectively, which confirms the high inhibitory activity of cinnamaldehyde in comparison with carvacrol.

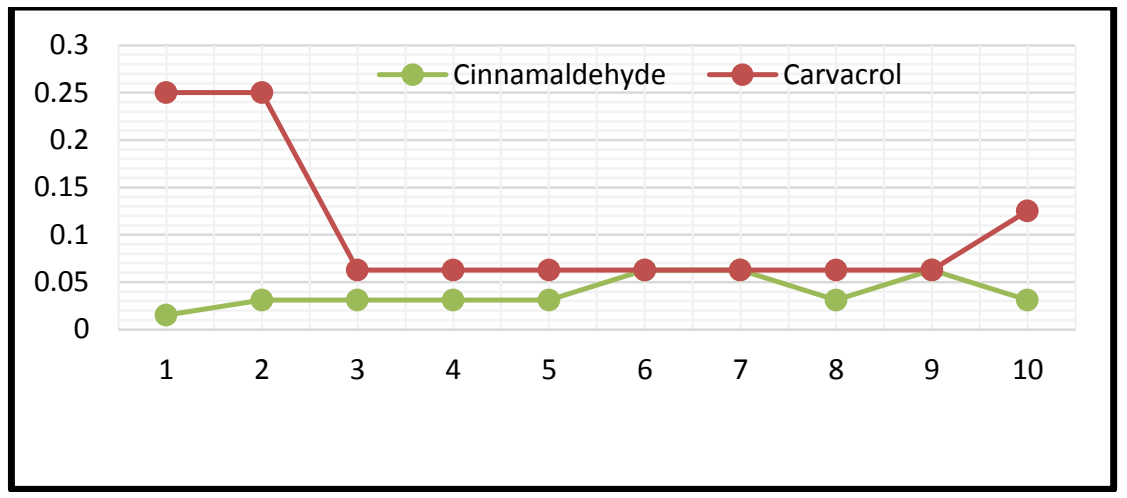

Figure 6:-MICs distribution of cinnamaldéhyde and carvacrol according to strains avian E.coli

The comparison of the MIC means d the diameters of the inhibition zones of the two products confirms the higher inhibitory activity of cinnamaldehyde in comparison with carvacrol. The antibacterial effect of cinnamaldehyde was demonstrated in liquid medium against Listeria monocytogenes and Escherichia coli with MICs equivalent to $0.25 \%$ for both bacterial strains (Hawkins and Savannah, 2014). A similar result was obtained in another work, where the cinnamaldehyde MIC against E. coli was $0.25 \%$ (Kim and $a l ., 2008$ ).

\section{Conclusion:-}

The cinnamon and oregano EOs and their major constituents have shown an important inhibitory effect on Escherichia coli strains of reference and of avian origin, with a remarkable antibacterial activity of cinnamon EO and its active ingredient, cinnamaldehyde, compared with oregano EO and its major constituent, carvacrol. The effect of the combination cinnamaldehyde and carvacrol was stronger than the activity of the two active ingredients tested separately on $E$. coli strains.

\section{Conflict of interest:}

We would like to confirm that there is no conflict of interest associated with this publication.

\section{Reference:-}

1. Bouhdid S., Skali S.N., Idaomar M., Zhiri A., Baudoux D., Amensour M., and Abrini J., (2008). Antibacterial and antioxidant activities of Origanum compactum essential oil. African Journal of Biotechnology Vol. 7 (10), pp. 1563-1570, 16 May. Available online at http://www.academicjournals.org/AJB ISSN 1684-5315.

2. Bouhdid S., (2009). Activités antimicrobienne et antioxydante des huiles essentielles. Application biotechnologique pour l'amélioration de la qualité des boyaux naturels. Thèse de Doctorat en Sciences (Spécialité : Biotechnologie, Discipline : Microbiologie). Université Abdelmalek essaadi. Faculté des Sciences.

3. Bouhdid S., Abrini2 J., Baudoux D., Manresa A., Zhiri A., (2012). Essential oils of oregano compact and cinnamon: antibacterial potency and mechanism of action. J Pharm Clin 2012; 31 (3) : 141-8.

4. Bounatirou S., Smiti S., Miguel M.G., Rejeb M.N., Nefati M., Costa M.M., Faleiro L., Figueiredo A.C., Baroso J.G., et Pedro L.G., (2007). Chemical composition, antioxidant and antibacterial activities of the essential oils isolated from Tunisian Thymus capitatus Hoff. et Link. Food Chemistry, 105, 146 R 155. 
5. Cao L., Yong Si J., Liu Y., Sun H., Jin W., LiZ., Hong ZhaoX., and Le Pan R., (2009). Essential oil composition, antimicrobial and antioxidant properties of Moslachinensis(Maxim). Food Chem., 115, 3801 Ŕ 805 .

6. Chorianopoulos N., Kalpoutzakis E., Aligiannis N., Mitaku S., Nychas G.J., et Haroutounian S.A., (2004). Essential oils of Satureja, Origanum, and Thymus species: Chemical composition and antibacterial activities against foodborne pathogens. J. of Agric. and Food Chem., 52, 8261 R 8267.

7. Clevenger J.F., (1928). Apparatus for the determination of volatile oil. J. Am. Pharm. Assoc., 17(4), $346-351$.

8. Dorman H. J. D., Deans S.G., (2000). Antimicrobial agents from plants: antibacterial activity of plant volatile oils. Journal of Applied Microbiology 88, 308-316

9. Elgayyar M., Draughon F.A., Golden D.A., Mount J.R., (2001). Antimicrobial activity of essential oils from plants against selected pathogenic and saprophytic microorganisms. Journal of Food Protection 64(7), 10191024.

10. Fabio A., Corona A., Forte E., and Quaglio P., (2003). Inhibitory activity of spices and essential oils on psychrotrophic bacteria. Microbiol., 26(1): 115-120.

11. Friedman M ., Henika P.R., Mandrell R.E., (2002). Bactericidal activities of plant essential oils and some of their isolated constituents against Campylobacter jejuni, Escherichia coli, Listeria monocytogenes, and Salmonella enterica. J Food Prot. 65:1545-60.

12. Gill A.O., Delaquis P., Russo P., et Holley R.A., (2002). Evaluation of antilisterial action of cilantro oil on vacuum packed ham. Int. J. of Food Microbiology, 73, 83 R 92.

13. Hammer K. A., Carson C. F., Riley T.V., (1999). Antimicrobial activity of essential oils and other plant extracts. Journal of Applied Microbiology 86, 985-990.

14. Hammou F., Skali S.N., Idaomar M., and Abrini J., (2011). The antimicrobial effect of Origanum compactum essential oil, nisin and their combination against Escherichia coli in tryptic soy broth (TSB) and in sheep natural sausage casings during storage at 25 and $7^{\circ} \mathrm{C}$. African Journal of Biotechnology Vol. 10(71), pp. 15998-16005, 14 November. Available online at http://www.academicjournals.org/AJB DOI: 10.5897/AJB11.1046

15. Hawkins, Savannah G., (2014). "Antimicrobial Activity of Cinnamic Acid, Citric Acid, Cinnamaldehyde, and Levulinic Acid Against Foodborne Pathogens". University of Tennessee Honors Thesis Projects. http://trace.tennessee.edu/utk_chanhonoproj/1701.

16. Inouye S., Takizawa T., Yamaguchi H., (2001). Antibacterial activity of essential oils and their major constituents against respiratory tract pathogens by gaseous contact. J AntimicrobChemother; 47:565-73.

17. Kalemba D., et Kunicka A., (2003). Antibacterial and antifungal properties of essential oils. Curr. Med. Chem. 10: 813-829.

18. Kim H., Park S., and Park H., (2008). Inactivation of Escherichia coli O157:H7 by cinnamic aldehyde purified from Cinnamomum cassia shoot. Food Microbiology 21: 105-110.

19. Matasyoh G.L., Matasyoh J.C., Wachira F.N., Kinyua M.G., ThairuMuigai W.A., Mukiama T.K., (2007). Chemical composition and antimicrobial activity of the essential oil of Ocimumgratissimum L. growing in Eastern Kenya. Afr. J. Biotechnol., 6(6) : 760-765.

20. Mith H., Duré R., Delcenserie V. ,Zhiri A., Daube G. , et Clinquart A ., (2014). Activités antimicrobiennes des huiles essentielles commerciales et de leurs composants contre les agents pathogènes d'origine alimentaire et les bactéries responsables de la détérioration des aliments. NourritureSciNutr . 2014 juil; 2 (4): 403-416. doi: $10.1002 / \mathrm{fsn} 3.116$

21. NCCLS. (1999). Performance standards for antimicrobial disk and dilution susceptibility tests for bacteria isolated from animals. Approved standard M31-A. Wayne, Pa: NCCLS; 1999.

22. Oussalah M., Caillet S., Saucier L., Lacroix M., (2006). Inhibitory effects of selected plant essential oils on the growth of four pathogenic bacteria: E. coli O157:H7, Salmonella Typhimurium, Staphylococcus aureus and Listeria monocytogenes. Food Control 18(5), 414-420.

23. Peñalver P., Huerta B., Borge C., Astorga R., Romero R., et Perea A., (2005). Antimicrobial activity of five essential oils against origin strains of the Enterobacteriaceae family. ActaPathologica, Microbiologica, etImmunologicaScandinavica, 113, 1 R 6.

24. PharmacopéeEuropéenne., (2011). Version 7.1 (avril 2011).

25. Remmal A., et al., (1993). Improved method for determination of antimicrobial activity of essential oils in agar medium. J. Essent. Oil Res., 5(2),179-184.

26. Remmal A., Bouchikhi T., Rhayour K., et al., (1993a). Improved method for the determination of antimicrobial activity of essential oils in agar medium. J Ess Oil Res 5/179-184. 
27. Rota M.C., Herrera A., Martínez R.M., Sotomayor J.A., et Jordán M.J., (2008). Antimicrobial activity and chemical composition of Thymus vulgaris, Thymus zygis and Thymus hyemalis essential oils. Food Control, 19, 681 Ŕ 687.

28. Senhaji O., Faid M., Kalalou I., (2007) Inactivation of E. coli 0157:H7 by essential oil from Cinnamomumzeylanicum. Brazilian Journal of infection disease, volume 11, issue 2, p. 234-236

29. Smith-Palmer A., Stewart J., Fyfe L., (1998). Antimicrobial properties of plant essential oils and essences against five important food-borne pathogens. Letters in Applied Microbiology 26, 118-12.

30. Sokmen A., Gulluce M., Akpulat H. A., Daferera D., Tepe B., Polissiou M., Sokmen M. et Sahin F., (2004). The in vitro antimicrobial and antioxidant activities of the essential oils and methanol extracts of endemic Thymus spathulifolius. Food Control, 15, 627 R 634.

31. Ultee A., Bennik M.H.J., Moezelaar R., (2002). The phenolic hydroxyl group of carvacrol is essential for action against the foodborne pathogen Bacillus cereus. Appl Environ Microbiol 68(4): 1561-8.

32. Valero M., Salmeron M. C., (2003). Antibacterial activity of 11 essential oils against Bacillus cereus in tyndallized carrot broth. Int. J. Food Microbiol. 85, 73-8.

33. Yamazaki, K., Yamamoto, T., Kawai, Y., Inoue, N., (2004). Enhancement of antilisterial activity of essential oils constituents by nisin and diglycerol fatty acid ester. Food Microbiology 21, 283-289

34. Yashphe J., Segal R., Breuer A., and Erdreich-Naftali G., (1979).Antibacterial activity of Artemisia herbaalba. J. of Pharma. Sci.. 68(7), 924-925. 